\title{
Managing Weapon System R\&M in the Post Cold-War Environment
}

\author{
Richard W. Price - U.S. Army Combined Arms Support Command • Fort Lee
}

Key Words: Weapon system, Management, Resources, Test and evaluation, Materiel Change, Decision risk, Post Cold-War, Decision making, Acquisition

SUMMARY \& CONCLUSIONS

Army R\&M engineers face numerous changes in the post cold-war era. These include both new constraints, opportunities, and challenges. New constraints impact on requirements determination and acquisition strategies. Reduced personnel and program funding will breed fewer active research and development (R\&D) programs. Department of Defense (DoD) policy changes are already placing tight scrutiny on R\&M at each major program decision point. Opportunities exist for R\&M improvements through increased use of Materiel Change Management (MCM) programs in lieu of new major programs. Increased use of post-fielding R\&M assessment offers an opportunity to identify R\&M-related cost savings and combat capability enhancements in currently fielded systems. Requirements will focus on new parameters that may more clearly identify potential operating and support cost savings. Innovation in test and evaluation will be imperative. Decision makers will no longer have the luxury of evaluation based on unlimited data. Increased use of simulation and decision risk analysis will be a necessity. In many cases, actual decision risk may be significantly higher than during the Cold War period. Hence, a much higher dependence on decision risk analysis will be experienced by $R \& M$ engineers.

\section{INTRODUCTION}

Global political events surrounding the turn of the decade impact on all societies. Economic fallout from the crumbling of the Berlin Wall and the subsequent dissolution of the Soviet Union created both short and long term implications. As a community, R\&M engineers involved in weapon system development experience these impacts in several ways. Personnel cuts were announced almost immediately, followed closely by announcements of major weapon system program cancellations or scale backs. For those who survive the manpower reductions, their traditional roles of determining user requirements and managing system acquisition remain largely intact. However, changes are anticipated in the conduct of daily operations.

The Post Cold-War climate poses several questions to $\mathrm{R} \& \mathrm{M}$ engineers and managers. What new constraints will affect planning, development, and fielding of weapon systems in the future? What opportunities should be exploited to improve weapon system R\&M in tomorrow's environment? What are the decision risk impacts surrounding weapon system $R \& M$ as a result of the changing world climate? This paper explores these questions and seeks answers to provide insight for the challenges ahead.

\section{FACING NEW CONSTRAINTS}

Perhaps the three program management constraints most often cited by weapon system managers during the Cold War were cost, schedule, and performance. Implications of German reunification and the collapse of the Soviet Union call for R\&M engineers to re-look these historical factors. As during the Cold War, the threat is still the driver behind materiel acquisition management. While a threat remains, there are certainly changes. New constraints have arisen as a result of these changes, some short term and others long term in nature. cost, schedule, and performance will remain primary considerations in future developments; however, the focus on each may change.

Primary new constraints are deep cutbacks in civilian and military personnel and steep reductions in monies for research, development, test, and evaluation (RDT\&E), and production of new weapon systems. Such resource reductions will breed other constraints such as less active research and development programs. Since the turn of the era, a prolific number of defense articles in all forms of media have forecast significant cutbacks in the number of future new major programs. Numerous senior executives, both public and private, expound the need to focus on fewer programs. The same group emphasizes the need to highly scrutinize "new starts" while concurrently strengthening the commitment to complete development of those selected.

The pendulum appears to have swung back in the direction of earlier years. Prior to conception of the Army Streamlined Acquisition Program, acquisition strategies followed the traditional four phase development process, with much emphasis placed on the demonstration/validation phase. A concept was not hastily passed into full development until it had thoroughly demonstrated its potential to meet user

US Government work not protected by US copyright 
requirements. Recent speeches by senior defense executives resound this philosophy for weapon system development in the new era ahead. Some leaders of large defense contractors share the same sentiment. With severely reduced resources, all want to be selective with which developments to pursue, and have confidence that once full development is initiated, the program will be supported to completion.

Another significant new constraint is change in published DoD acquisition policies. However, more so than published policy, actions by senior decision makers foretell future directions. In two recent cases involving weapon systems in early development, top level decisions to resolve controversial R\&M issues guarded against premature rejection of the developmental system although demonstrated R\&M performance was very poor. This philosophy has been undergirded over the past two years by directives from senior executives. R\&M exit criteria must now be established at each major decision point to clearly signal the need to abandon developmental efforts. In keeping with the unwritten philosophy, these have thus far been very generous to program managers and contractors. Additionally, entrance thresholds must be established to signal a system's preparedness to proceed into the next phase of development. Such criteria will be used in the future to place tight scrutiny on $R \& M$ and other performance and supportability parameters at each decision point throughout the life cycle.

\section{SEIZING NEW OPPORTUNITIES}

Opportunities exist amidst the changes. Reliability engineers must look for promising opportunities to improve weapon system R\&M in tomorrow's environment. One prime opportunity is through increased use of Materiel Change Management (MCM) programs. During the Cold War these programs, known earlier as Product Improvement Programs (PIP), focused almost entirely on enhancing performance capability. A smaller number of them were funded to correct safety deficiencies. Practically none emphasized reliability, maintainability, and overall supportability. In most cases, product improvement efforts had adverse effect on system R\&M characteristics. Adding more performance capability to an existing weapons platform without concurrently improving its existing $R \& M$ obviously degraded overall system R\&M characteristics. Moreover, product improvements oriented to improve basic system reliability and maintainability lacked the glamour of those enhancing performance. Such lack of glamour, or conversely the presence thereof, seemed to correlate directly with funding approved for MCM programs. The Post Cold-War period may offer an opportunity to reverse this trend.

With less monies available for new major research and development, materiel change programs focused on enhancing the R\&M of existing weapon systems offers one of the few future avenues to improve or sustain combat capability of current systems. The changed threat and the outstanding performance of many weapon systems during Operations Desert Shield and Desert Storm further the argument that future MCM programs should concentrate on improving reliability and supportability.

A second opportunity may be found in the former unheralded minor programs. The end of the Cold War plus the successes of Operations Desert Storm and Shield have greatly affected public and political opinion in the United States. Many congressmen have called for severe cutbacks and delays in some major systems in early stages of concept exploration. In fact, some systems have been cancelled, significantly delayed, or severely restructured.

While numerous existing systems perform well, attention to supportability details waned during their development. The Army carried a large number of minor systems on its development books during the Cold War. In the funding game, most of these suffered relative to the glamorous combat systems. Partial blame can be attributed to failure to link essential support systems to their associated combat systems. This should not pose a problem in the future as the Army now has a process to identify these critical linkages. At all decision levels involved in funding, decision makers will know negative implications associated with cuts in combat service support systems as they impact combat systems. System for system, combat service support systems generally cost much less than the major weapon systems viewed via television in homes around the world during Operations Desert Shield and Storm. In the Post Cold-War era, the greatest return on investment of defense dollars may come from funding combat service support systems. Importance of R\&M cannot be underemphasized in these systems as they are integrally related to the overall reliability and readiness of combat systems.

A third promising opportunity is through increased activity in post-fielding R\&M assessment. Few Army reliability engineers spent time during Cold War years looking for potential improvements in weapon systems after they were fielded. Practically all available manpower was concentrated on systems under development. Reliability engineers had all the work they could do just to keep up with the stream of 
requirements documents being written. Little time was available to investigate demonstrated $R \& M$ performance of fielded systems. Only glaring problems with major systems received attention. Furthermore, only limited data is collected on fielded systems, and that only for a few systems. Its accuracy and value is controversial. Collection and analysis of such data within an Army unit is practically impossible. The form in which it is gathered is much too gross for meaningful detailed analysis by reliability engineers. With fewer active programs expected in the Post Cold-War environment, engineers may have time to exploit this potentially fertile area.

Amid constraints discussed earlier, a fourth opportunity was created with the advent of new DoD directives governing future weapon system development. Statements of requirements for new systems must now contain a "logistics reliability" parameter. Much debate among reliability engineers was generated by this new requirement. Numerous proposals have been made as to what this parameter should be. Thus far, disagreement has been widespread. Though consensus has not been reached, each proposal captures the essence of senior decision makers' intent in adding the new requirement. A void existed among the many informative R\&M parameters used for years. Terms such as mission reliability, system reliability, operational reliability, hardware reliability, and others have been used extensively in the past. However, no measure has been used to effectively specify and measure the frequency with which a system places demand on support resources. These include maintenance personnel, support equipment, facilities, and parts. Army transportation, maintenance, and supply systems are all impacted by weapon system failures. With the Post Cold-War resource constraints, this new requirement could not be more timely. Weapon system equipment readiness, while also a function of reliability and maintainability, is mostly controlled by the responsiveness of the overall logistics system and its management. Through data made possible through logistics reliability parameters, Army logistics planners may be able to improve the design and management of their support systems. Although controversial, this requirement will cause reliability engineers to focus on a lower-order parameter that, in addition to enhancing readiness, may divulge significant savings in operating and support costs.

\section{MEETING NEW CHALLENGES}

Changes brought by the Post Cold-War era offer reliability engineers many challenges. Constrained resources create one challenge that is particularly difficult yet interesting. In a time of fewer dollars, how can sufficient test and evaluation (T\&E) be structured to provide adequate information for decision making. Obviously, as during the Cold War, a reasonable decision risk is desired. This issue certainly does not lack for controversy. Already much debate has been generated among the R\&M engineering community.

In the previous era, most weapon systems Test and Evaluation Master Plans (TEMP) called for enough data generation to practically make evaluation a misnomer. Usually, evaluators could simply render a simple "met" or "not met" conclusion with very little decision risk. Though program managers fought against the cost and length of such extensive testing programs, they usually gave in and provided sufficient funding for the T\&E and adequate time for its accomplishment in the program schedule. The Post Cold-War environment will not provide such a luxury.

Decision makers will no longer have the luxury of evaluation results based on unlimited amounts of actual test data. The R\&M community must search for innovative ways to test and evaluate future weapon systems. Increased use of other tools such as simulation and decision risk analysis will be a must. Past years saw a great deal of duplicative testing, particularly technical versus user. Army $T \& E$ regulations for years have provided for and have encouraged use of combined testing. Merging of test data bases has likewise been promoted. More must be done in these areas. Operational and technical test and evaluation agencies within the Army are separate entities -independent as their names imply. This perhaps has contributed to their reluctance to collaborate in the past. However, resource pressures leave no option but to reverse this trend.

Strides have been made in recent years to bring these two communities closer. Technical testing used to vaguely, if at all, resemble how equipment and systems are used by soldiers in the field. Recently, technical testers have strived to plan and execute their tests as close as possible to a weapon system's actual mission profiles. This improves ability to merge this data with that from operational testing. On the other side, operational testing is very expensive and difficult to plan due to unavailability of military units to use as test players. This condition will only be worsened by cutbacks in the number of uniformed Army personnel. Opposition has always existed to removing soldiers from their job of training to serve as test players for some future weapon system they may never see fielded during their careers. All of this ultimately leads to the issue of decision risk. Relatively little decision risk 
analysis was used in previous years. Confidence associated with test results has largely not been an issue because extensive testing was fully resourced. Army regulations formerly spoke of demonstrating $R \& M$ and other requirements at a "high confidence" prior to fielding. Although not specified, this term became almost universally interpreted as an 80 percent lower confidence limit, regardless of the scope of a program. Such wording has found its way out of many regulations; however, most $\mathrm{T} \& \mathrm{E}$ agencies still subscribe to the past interpretations as if sworn to by an oath. The environment has changed. Such blind following must necessarily pass.

Reliability engineers are challenged in the Post Cold-War to delve more deeply into decision risk analysis. In many cases, actual decision risk borne by senior decision makers may be significantly higher, due to resource constraints, than during the Cold War period. A stronger reliance on decision risk analysis as a tool may help reliability engineers respond to the challenge of best describing R\&M risks to senior executives. In this way R\&M professionals will play a vital role in critical decisions for weapon systems of the future.

\section{ACKNOWLEDGEMENTS}

The author gratefully acknowledges the assistance provided by CPT Ricardo Gonzalez and David C. Henkel of the RAM Engineering Division, U.S. Army Combined Arms Support Command, in the preparation of this paper and presentation slides.

Richard W. Price, P.E.

$$
\text { BIOGRAPHY }
$$

U.S. Army Combined Arms Support Command

ATTN: ATCL-MEE

Fort Lee, Virginia, 23801-6000 USA

Richard W. Price is Eastern Regional Manager of R\&M engineering for the U.S. Army Combined Arms Support Command, Fort Lee, Virginia. He is responsible for the development and approval of weapon system R\&M requirements and for the $R \& M$ assessment of fielded systems and those being developed. He began working for the Army as an Engineer in 1976 and has been working in R\&M since 1982 . He received the first annual R\&M Engineer of the Year Award in 1988 from the U.S. Army Training and Doctrine Command. In 1991, he received the Commander's Award for Civilian Service from the Commander, U.S. Army Combined Arms Support Command. His degrees include Bachelors and Masters of Engineering from Old
Dominion University, Norfolk, Virginia, and a Master of Business Administration from Florida Institute of Technology. $\mathrm{He}$ is a member of the American Society of Civil Engineers, the Civil Engineering Visiting Council at Old Dominion University, and is a registered professional engineer in the state of Virginia. 